\title{
Prevealence of Cleft Lip and Palate in Benghazi_Libya
}

\author{
Iman Abdelgader ${ }^{1 *}$, Tayisier Ganeiber ${ }^{2}$, Zakia Nabous ${ }^{3}$ and Nairouz Elbakosh ${ }^{4}$ \\ ${ }^{1}$ Iman Abdelgader, Assistant professor, Department of orthodontics, faculty of dentistry, Benghazi University \\ 2Tayisier Ganeiber, Assistant lecturer, Department of orthodontics, faculty of dentistry, Benghazi University \\ 3Zakia Nabous, Department of orthodontics, faculty of dentistry, Benghazi University \\ 4Nairouz Elbakosh, Department of orthodontics, faculty of dentistry, Benghazi University
}

*Corresponding author: Iman Abdelgader, President of Libyan orthodontic society, Associate professor, department of orthodontics, Faculty of dentistry, Benghazi university, Libya.

Received Date: September 08, 2020

Published Date: September 18, 2020

\begin{abstract}
Introduction: cleft lip and palate is one of the most common developmental defects that affect the head and neck region. This might occur if the fusion between the embryological processes fail. Birth of a baby with a cleft lip or palate is an exhausting and emotional problem which needs Longterm and Multidisciplinary management by plastic surgeon, otolaryngologist, geneticist, pediatrician, social worker, periodontist, orthodontist, and a speech and language specialist The etiology is unknown but there are many predisposing factors which might lead to this defect.
\end{abstract}

Aim: The aim of this study is find out the prevalence of cleft lip and palate and to screen the predisposing factors in newborn babies with cleft lip and palate in Benghazi hospitals

Material and method: A Data were Collected from the Archives of Benghazi medical Center and Benghazi Pediatric Hospital to find out the incidence of cleft lip and palate among newborn. the following informations were registered: Date of birth-Birth weight-type of cleft-other congenital defect-age of the mother, her medical condition and drug consumption during pregnancy-age of the father and smoking habit - family history of clefts. further Contacts were done by phone calls with the parents to collect more information. full information were acquired from 26 cases out of 43 registered cases of clefts. Statistic analyses using IBM SPSS V.22 Software were done to find out the correlation of predisposing factors with clefts through chi-square.

Results: From the recorded 43 cases of cleft lip is $19.5 \%$, cleft palate $48.8 \%$, cleft lip \& palate $31.7 \%$. Males were affected more than females (males $65 \%$ vs females $35 \%$ ). in the 26 cases Drug consumption during pregnancy was found $61.5 \%$, mother medical problems $53.8 \%$, family history from the mother side $7.7 \%$ and from the father side $11.5 \%$, father smoking habit $46 \%$.

Conclusion: The $\mathrm{p}$ value from the predisposing factors was insignificant. The male cases rate was higher than females. Future studies should be done to obtain more information.

\section{Introduction}

The most confusing congenital malformation of the head and neck region that encounter plastic Surgeons and Orthodontists are clefts of the lip and palate, it is estimated to account for more than $60 \%$ of all head and neck anomalies Gorlin, Cohen, Hannekam (2001) [1] many problems may associated with these defects such as feeding and speech difficulties, nasal deformitiy, hearing impairment, malocclusion, cosmetic and social

acceptance Peterson, et al. (2008) [2]. Such deformities requires multidisciplinary intervention by large group of specialists from birth till adulthood that will cost the patients families and the health system a lot of time and money Chung, Ching, Morton (1974) [3] Little, Munger (2004) [4]. The etiology of Cleft lips and/or palates is not clear. However, it is believed to be related by multifactorial causes including environmental and genetic factors Jones (1993) [5] Nemana, Marazita, Melnick (1992) [6]. In an effort to elucidate 
the various factors responsible for these anomalies, increasing use has been made of vital statistics from many parts of the world.

Most surveys have recorded cleft lip and palate as a single incidence. However, the primary palate (lip, anterior septum, and premaxilla) develops from the fourth to the seventh week of gestation and in a different manner from the secondary palate (hard and soft palate) which is formed from the seventh to the twelfth week Calzolari, et al. (1998) [7]. Therefore, it would appear appropriate to separate these two entities when recording their occurrence and there possible linked environmental factors, as well as the combination of cleft lip and palate. The primary aim of this study was to evaluate the prevalence of cleft lip \& palate in Benghazi city_Libya. Additional aims were to evaluate the ratio of different possible etiological factors and analysis of these data to throw light on possible etiological mechanisms of this deformity.

\section{Materials and Methods}

The present study was a retrospective, observational and analytic study. The data of babies born from 2014 untill August 2017 for this research was collected from the archive's files of two major hospitals in Benghazi city_ Libya: Benghazi medical center and Benghazi Pediatric hospital. Other information's were collected by direct contact with parents. The cleft samples data were compared for variable such as gender, type of cleft, mother medical condition, drug in take, smoking father and family history of both parents. Statistical analysis was performed using IBM SPSS V.22 software. Using frequency analysis and crosstabs-Pearson ChiSquare, followed by Spearman correlation.

\section{Results}

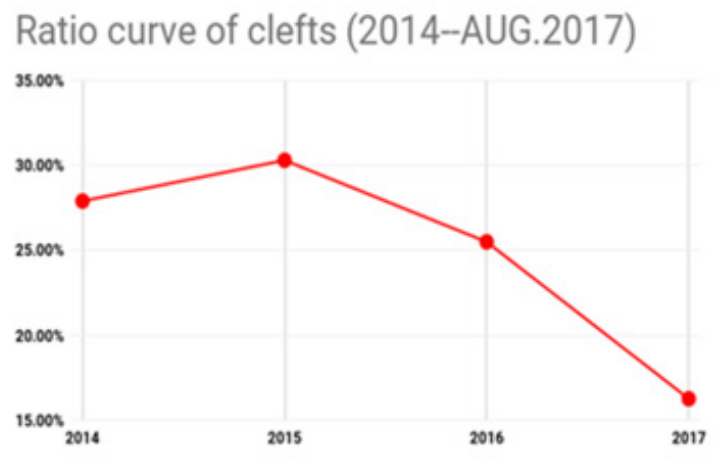

Figure 1: Ratio curve of clefts.

From a total of 29610 live baby born, 26 cleft lip and palate patients were recognized and registered with annual distribution as detailed in (Figure 1). He greatest number of cleft patients occur in 2015 and the fewest in 2017. The distribution by gender showed that male are more affected by this deformity then female 16 were boys $(61.5 \%)$ and 10 were girls $(38.5 \%)$ as it can be seen in (Figure
2 , 3). Out of 26 patients there was 12 patients with cleft palate (46.2\%), 8 patients with cleft lip (30.8) and 6 patients with cleft lip and palate $(23.1 \%$ ) as it is presented in (Figure 4). (Figure 5) may indicate strong relation between drug in take during pregnancy and the incidence of deformity. From the 26 patients there was a 16 case $(61.5 \%)$ with history of drug in take during pregnancy. Only 5 mothers of the 26 sample patients had related syndrome(?) (19.2\%).

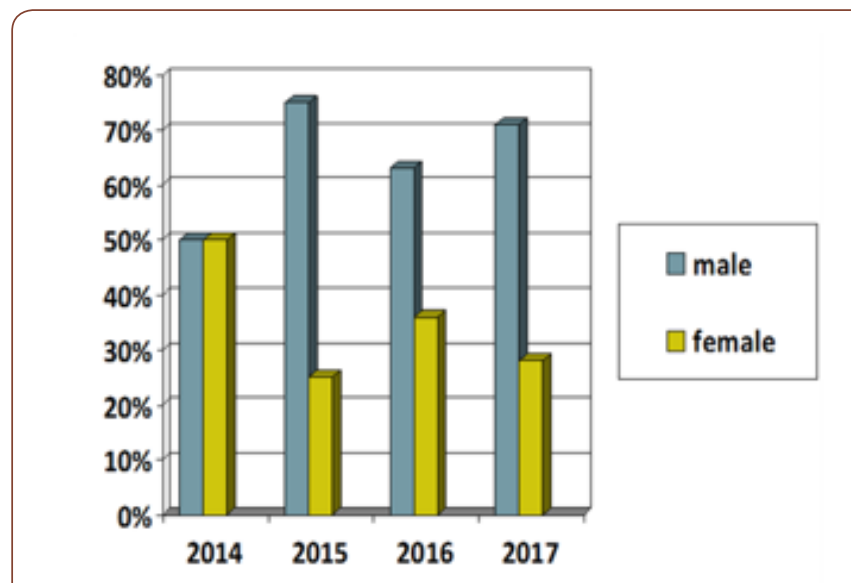

Figure 2: Male to female ratio.

male \& female ratio from 2014 to 2017

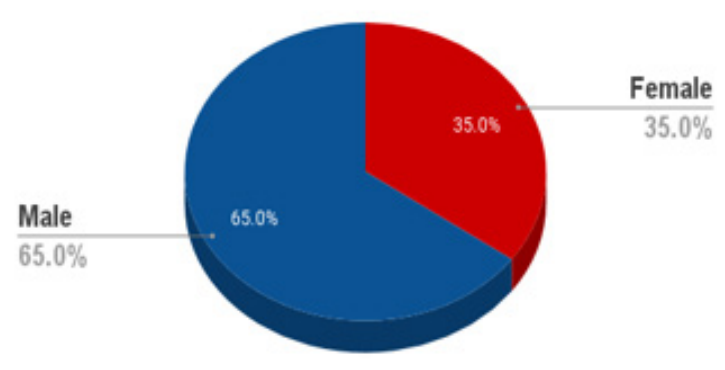

Figure 3: Male to female ratio.

\section{Cleft types ratio 2014-2017}

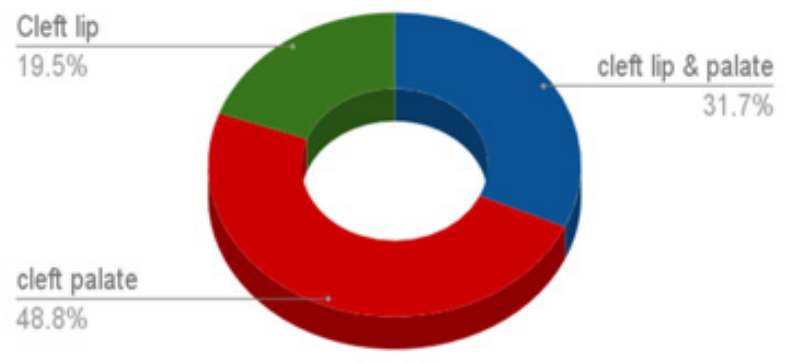

Figure 4: Cleft types ratio. 


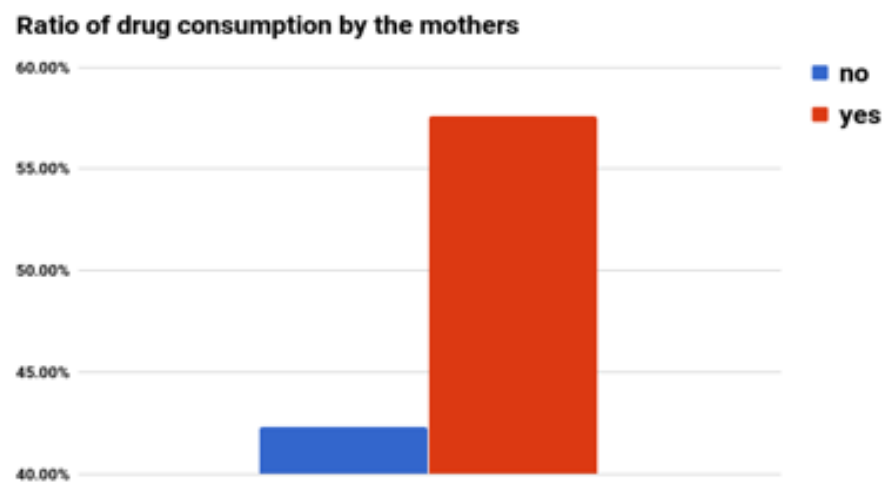

Figure 5: Ratio of drug consumption by mother.

The records from the hospitals showed that 8 mothers (30\%) had long period of pregnancy i.e above average, which is 36 week of gestation, while only 1 mother $(3.8 \%)$ had short period of pregnancy around 33 week of gestation(?). There was a history of other medical conditions (hypertension, diabetes, heart diseases, etc.) in 14 cases of the patient's mother (53.8\%). The investigations showed that 12 of the cleft's patients' father were smokers (46.2\%) as it can be seen in (Figure 6). There was a family history of cleft lip and palate in 3 patients' father (11.5\%) and 0nly 2 of patients' mother (7.7\%) (Figure 7) (Table 1).

\section{Fathers smoking ratio in 26 cases}

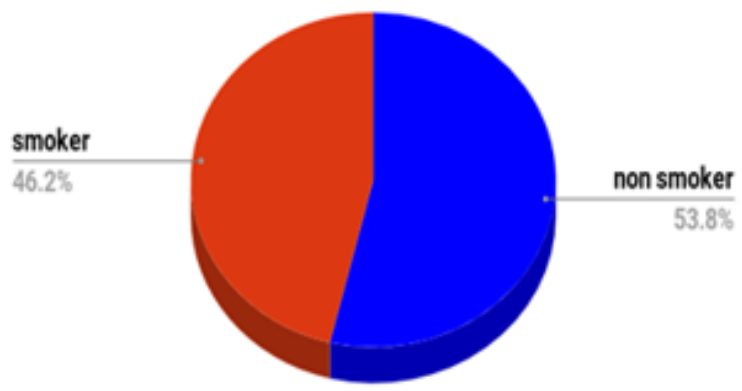

Figure 6: Ratio of father smoking.

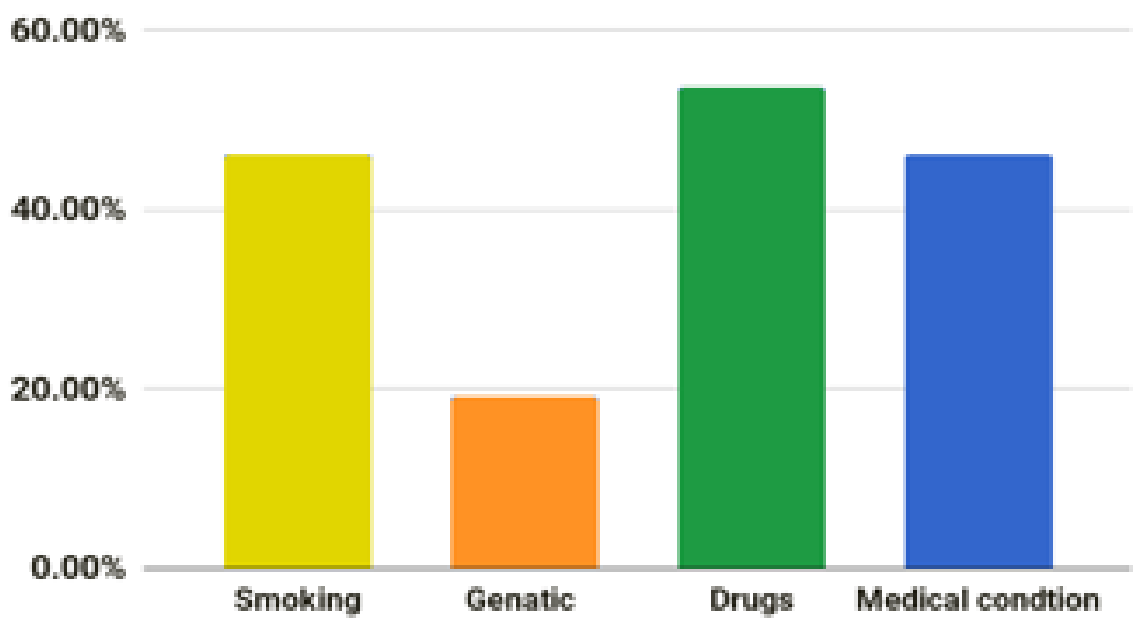

Figure 7: Etiology Ratio. 
Table 1: Pearson Chi-Square Tests.

\begin{tabular}{|c|c|c|c|}
\hline \multirow{2}{*}{ Comparison between variables } & \multirow{2}{*}{ Pearson Chi-square Sig. (X2) } & Value & Spearman Correlation \\
\cline { 2 - 4 } & & -0.129 & 0.453 \\
\hline Cleft with gender & 0.227 & 0.079 & 0.647 \\
\hline Cleft with drug & 0.584 & 0.207 & 0.226 \\
\hline Cleft with mother syndrome & 0.397 & 0.09 & 0.603 \\
\hline Cleft with mother history & 0.662 & 0.346 & 0.038 \\
\hline Cleft with mother medical condition & 0.075 & 0.079 & 0.647 \\
\hline Cleft with father history & 0.551 & 0.044 & 0.799 \\
\hline
\end{tabular}

\section{Discussion}

This study showed that the incidence of cleft lip and $\backslash$ or palate in Benghazi was 0.875 per 1000 live birth. This is considered a low incidence of cleft deformity when it compared to other part of the world Cohen, 2002 [8], Gregg, Boyd, Richardson (1994) [9], Kozel (1996) [10], It could be related to the fact that Libyan women in general live in a very conservative society where smoking and alcohol intake among female is almost zero, and there is a lot of researches suggested alcohol and smoking to have teratogenic effect on fetous development during pregnancy Calzolari, et al. (1998) [7]. The research analysis showed that there was differences in the gender distribution of the study sample. $65 \%$ of patients were boys. which mean male are more likely to be effected by the deformity. The same result also reported in Europe and the USA Gregg, Boyd, Richardson (1994) [9], Kozel (1996) [108]. However, in other parts of the world the ratio between male and female are either equal like the result of study made in Nigeria Iregbulem (1982) [11] or higher in female which is the result of study made in Sudan Suleiman, et al., (2005) [12].

The type and extent of cleft defects vary according to race. In study published on a Caucasian population, the prevalence of Cleft lip was $25 \%$, Cleft lip and palate $50 \%$, and cleft palate $25 \%$ Croen, et al. (1998) [13]. A study on an African population, done in Nigeria showed the prevalence of Cleft lip 49\%, Cleft lip and palate $32 \%$ and Cleft palate 19\%. Iregbulem (1982) [11] Our study showed the prevalence of Cleft lip to be $30 \%$, Cleft lip and palate $23.1 \%$, and cleft palate $46 \%$. The reason for the low percentage of Cleft palate in other studies could be due to under reporting of the problem. cleft palate may be undiagnosed at birth and could have been missed in the evaluation of patients.

According to some authors Trigos, Ontiveros (1994) [14], the type of the mother medical condition could increase the incidence of congenital malformations. Viruses and bacteria, to a lesser degree, may traverse the placenta and reach embryonic tissue. Also, poor oxygen, blood supply and malnutrition which associated with some systemic disease may have negative impact on the newborn development at different stage. The statistical analysis of our study reveal that there is a relation between the deformity incidence and the mother general medical condition. $53 \%$ of the mother's patient have been diagnosed with at least one poor medical condition (hypertension, diabetes, heart disease, etc.). This finding could be important. However, a detailed investigation should conducted to indicate which and how these systemic diseases may effect the embryonic development.

Many experts Saver, Evans (1980) [15] believes there is a connection between mother in takes of some types of medical drugs during pregnancy with the pathogenesis of cleft deformity. They claim that the exposure to certain chemical agent during the first trimaster may interfere with the normal development of lip and palate. These suspicious showed up in our result. (61.5\%) of the patient's mother were taking medical drug during their pregnancy. A relation could be found here nevertheless further research on the exact type of chemical agents and when and how they disturb the normal growth should be done. According to the WHO 2016 report, the tobacco smoking epidemic is one of the largest public health problems globally and the number of nonsmokers exposed to secondhand smoke (SHS) has been steadily increasing WHO media center Tobacco fact sheet, 2016 [16]. Of additional concern is that maternal SHS exposure is also associated with adverse birth outcomes such as low birth weight, spontaneous abortion Leonardi Bee, Britton and Veen (2001) [17], and birth defects Lindbohm, Sallmen, Taskinen (2002) [18]. Our investigation studied the relation between the incidence of the cleft and smoking father (46.2\%) of the patient's father were smoker. There could be a relation between secondary smoking and the etiology of the cleft lip and palate, again wider studies on bigger simples need to be done.

Our understanding of the etiology and the pathogenesis of orofacial cleft remain relatively poor. Experts believe it involve both genetic and environmental factors playing an important role at the molecular level during embryogenesis Jones, Bronsky (1995) [19]. Primery evidence for a genetic role has been available, the siblink risk for cleft lip and palate is 30 times higher than that of the normal population prevalence Mitchell and Risch (1992) [20]. Our research found only 2 of patient's mother (7.7\%) and only 3 of patient's father (11.5\%) with history of cleft Lip and/or Palate running in their families. This prove that environmental factors play important role and an important area of future research will be needed to unravel interaction that occur between candidate genes and environmental factors during early development of embryo. 


\section{Conclusion}

Based on the results obtained in this research we conclude that: The overall incidence of cleft lip and/or palate in Benghazi Libya was 0.875 per 1000 live birth. Male are more vulnerable to this deformity with a ratio of 1.6: 1 . The analysis of etiology ratio showed that mother of patients with poor medical condition and drug in take during pregnancy were significantly different from genetic and smoking father group.

\section{Acknowledgement}

None.

\section{Conflict of Interest}

No conflict of interest.

\section{References}

1. Gorlin RY, Cohen MM and Hannekam R (2001) Syndromes of the head and neck, ( $4^{\text {th }}$ Edn,). Oxford University Press: New York, Oxford, USA.

2. Peterson LJ, Ellis E, Hupp JR, Tucker MR (2008) Contemporary Oral \& Maxillofacial Surgery. ( $5^{\text {th }}$ Edn, ). St Louis, USA.

3. Chung CS, Ching GHS, Morton NE (1974) A genetic study of cleft lip and palate in Hawaii: II. Complex segregation analysis of genetic risks. Am J Hum Genet 26: 177-188.

4. Little J, Cardy A, Munger RG (2004) Tobacco smoking and oral clefts: a meta-analysis. Bull World Health Organ 82: 213-218.

5. Jones MC (1993) Facial clefting: Etiology and developmental pathogenesis. Clin Plast Surg 20:599-606.

6. Nemana LJ, Marazita ML, Melnick M (1992) A genetic analysis of cleft lip with or without cleft palate in Madras. India Am J Med Genet 42: 5-9.

7. Calzolari E, Milan M, Carazzuti GB, Cocchi G, Gandini E, et al. (1998) Ep idemiological and genetics study of 200 cases of oral cleft in the Emilia Romagna region of northern Italy. Teratology 38: 559-564.

8. Cohen MM (2002) Perspective on craniofacial anomalies, syndromes and other disorders. In: Lin KY, Ogle RC, Jane JA, (Eds,). Craniofacial sur- gery: Science and surgical technique. WB Saunders: Philadelphia, USA pp: 448-453.

9. Gregg T, Boyd D, Richardson A (1994) The incidence of cleft lip and palate in Northern Ireland from 1980-1990. Br J Orthod 21: 387-392.

10. Kozel V (1996) Epidemiology of orofacial clefts in Solvenia, 1973-1993: Comparison of the incidence in sex European countries. J Craniomaxillofac Surg 24: 378-382.

11. Iregbulem LM (1982) The incidence of cleft lip and palate in Nigeria. Cleft Palate J 19: 201-215.

12. Suleiman AM, Hamzah ST, Abusalab MA, Samaan (2005) KT Prevalence of cleft lip a hospital-based population in the Sudan. Int J Paediatr Dent 15: 185-189.

13. Croen LA, Shaw GM, Wasserman CR and Tolarová MM (1998) Racial and ethnic variations in the prevalence of orofacial clefts in California 19831992. Am J Med Genet 79: 42-47.

14. Trigos I and Saavedra-Ontiveros M (1994) Reconstructive and Aesthetic Plastic Surgery, (2 ${ }^{\text {nd }}$ Edn,) vol II, Bogota, Colombia: Masson- Salvat 15191532.

15. Saver GJ, Evans CA (1980) Hypervitaminosis and matrix alterations in maxillary implants from $16^{\text {th }}$ day rat embryos. Teratology $21: 123-130$.

16. World Health Organization (2016) WHO Media center Tobacco Fact sheet.

17. Leonardi Bee J, Britton J, Venn A (2011) Secondhand smoke and adverse fetal outcomes in nonsmoking pregnant women: a meta-analysis. Pediatrics 127: 734-741.

18. Lindbohm ML, Sallmen M, Taskinen H (2002) Effects of exposure to environmental tobacco smoke on reproductive health. Scandinavian journal of work. Scand J Work Environ Health 28: 84-96.

19. Jones MC, Bronsky PT (1995) Prenatal craniofacial development: new insights on normal mechanisms. Critical Reviews in Oral Biology and Medicine 6: 25-79.

20. Mitchell LE, Risch N (1992) Mode of inheritiance of non-syndromic cleft lip with or without cleft palate: a reanalysis. Am J Hum Genet 51: 323332. 